\title{
Retraction Note: Release-Active Dilutions of Diclofenac Enhance Anti-inflammatory Effect of Diclofenac in Carrageenan-Induced Rat Paw Edema Model
}

\author{
Sachin S. Sakat, ${ }^{1}$ Kamaraj Mani, ${ }^{1}$ Yulia O. Demidchenko, ${ }^{2}$ Evgeniy A. Gorbunov, ${ }^{2,3}$ \\ Sergey A. Tarasov, ${ }^{2}$ Archna Mathur, ${ }^{1}$ and Oleg I. Epstein ${ }^{2}$
}

Retraction Note: Inflammation (2013) 37(1):1-9

https://doi.org/10.1007/s10753-013-9705-0

The Editor has retracted this article [1] because there are concerns about the scientific validity of the study and undeclared conflicts of interest. Specifically, the reagent is diluted beyond the point at which any active molecules are expected to be present and there is no molecular analysis to support the presence of molecules at these dilutions. Additionally, the following statement of conflict of interests should have been included: Y.O. Demidchenko, E.A. Gorbunov, S.A. Tarasov, and O.I. Epstein are affiliated with OOO "NPF "Materia Medica Holding" that provided funding for this work and manufactures the release-active solution used in this study. These concerns have caused the Editor to lose faith in the reliability of the findings.

E.G. disagrees with this retraction. S.T. has not stated whether he agrees or disagrees with this retraction notice. S.S., K.M., Y.D., A.M., and O.E. did not respond to correspondence about this retraction.

The online version of the original article can be found at https://doi.org/ 10.1007/s10753-013-9705-0

${ }^{1}$ Dabur Research Foundation, 22, Site IV, Sahibabad, Ghaziabad, Uttar Pradesh 201-010, India

${ }^{2}$ OOO "NPF "MATERIA MEDICA HOLIDING”, 3rd Samotyochny per., 9, Moscow, Russian Federation 127473

${ }^{3}$ To whom correspondence should be addressed at OOO "NPF "MATERIA MEDICA HOLIDING", 3rd Samotyochny per., 9, Moscow, Russian Federation127473. E-mail: gorbunovea@materiamedica.ru

\section{REFERENCE}

1. Sakat, S.S., K. Mani, Y.O. Demidchenko, E.A. Gorbunov, S.A. Tarasov, A. Mathur, and O.I. Epstein. 2014. Release-active dilutions of diclofenac enhance anti-inflammatory effect of diclofenac in carrageenan-induced rat paw edema model. Inflammation 37: 1-9. https://doi.org/10.1007/s10753-013-9705-0.

Publisher's Note Springer Nature remains neutral with regard to jurisdictional claims in published maps and institutional affiliations. 